"NOTICE: this is the author's version of a work that was accepted for publication in Ecological Economics. Changes resulting from the publishing process, such as peer review, editing, corrections, structural formatting, and other quality control mechanisms may not be reflected in this document. Changes may have been made to this work since it was submitted for publication. A definitive version was subsequently published as:

Catarina Roseta-Palma, Alexandra Ferreira-Lopes, Tiago Neves Sequeira, Externalities in an endogenous growth model with social and natural capital, Ecological Economics, Volume 69, Issue 3, 15 January 2010, Pages 603-612, ISSN 0921-8009, http://dx.doi.org/10.1016/j.ecolecon.2009.09.008 " 


\title{
Externalities in an Endogenous Growth Model with Social and Natural Capital
}

\author{
Catarina Roseta-Palma ${ }^{a} \quad$ Alexandra Ferreira-Lopes ${ }^{b}$ \\ Tiago Neves Sequeirac
}

\begin{abstract}
Models of economic growth are typically based on the use of one or more stocks of productive assets to create goods for utilitygenerating consumption. The roles played by man-made capital, natural capital, and human capital have been explored in the literature, and more recently the notion of social capital has been brought to the fore. This paper provides an attempt to construct an inclusive model of growth, analysing externalities and distortions due to market failures linked with social capital and environmental problems.

JEL Classification: O13, O15, O41, Q20.

Keywords: Human Capital, Social Capital, Natural Capital, Produced Capital, Economic Growth.
\end{abstract}

\footnotetext{
${ }^{\mathrm{a}}$ corresponding author; ISCTE - Lisbon University Institute, Economics Department, ERC-UNIDE, and DINÂMIA. Av. Forças Armadas, 1649-026 Lisboa, Portugal. Tel.: +351 217903438; Fax: +351 217903933; e-mail: catarina.roseta@iscte.pt. Catarina Roseta-Palma acknowledges financial support from FCT, scholarship SFRH/BSAB/861 $/ 2008$.

${ }^{\mathrm{b}}$ ISCTE - Lisbon University Institute, Economics Department, ERC-UNIDE, and DINÂMIA. Av. Forças Armadas, 1649-026 Lisboa, Portugal. Tel.: +351 217903901; Fax: +351 217903933; e-mail: alexandra.ferreira.lopes@iscte.pt. Alexandra FerreiraLopes acknowledges financial support from FCT.

${ }^{\mathrm{c}} \mathrm{UBI}$ and INOVA, UNL. E-mail: sequeira@ubi.pt. Management and Economics Department. Universidade da Beira Interior. Estrada do Sineiro, 6200-209 Covilhã, Portugal. Tiago Neves Sequeira acknowledges financial support from POCI/FCT.
} 


\section{Introduction}

Models of economic growth are typically based on the use of one or more stocks of productive assets that are drawn upon to create goods for utilitygenerating consumption. The role of natural resources or, more generally, environmental assets has been thoroughly analysed by many authors, of which Smulders (2005) gives an excellent non-technical summary. Whether non-renewable or renewable resources are considered, the crucial factors initially seen to determine the possibility of growth (in the sense of a sustained increase in consumption) were the substitutability between natural resources and produced capital, and the drive provided by technical change (see, for example, the seminal books by Dasgupta and Heal, 1979, and Heal, 1998). Additionally, many authors have since emphasized that environmental resources often have a public good character, so that without proper policies markets are unable to ensure their adequate allocation, thus jeopardizing growth opportunities. Such policies include emission or resource taxes, permit trading, and pollution abatement activities. For instance, Bovenberg and Smulders (1995) present a model where environmental quality affects welfare and productivity directly, and Xepapadeas (2005) is a survey of growth models with environmental pollution.

Outside the realm of environmental economics, endogenous growth theory has emphasized the contribution of human capital, or knowledge, which unlike produced capital is not necessarily subject to diminishing returns. When such models do take natural capital into account, knowledge can supply the thrust to keep consumption rising in spite of the bounds placed on humanity by the natural environment. A well-known example is provided by Aghion and Howitt (1998). Still, the growth of knowledge may not be altogether positive for the environment if it promotes an expansion of resource-based consumption, so such beneficial outcomes cannot be taken for granted, as discussed in Ehrlich et al (1999). At any rate, as noted by Rodrigues et al (2005), it is at least possible for the "material" side of the economy to stop growing, achieving a biophysical steady state, while the intellectual side continues to rise "at the pace allowed by knowledge formation and dematerialization".

More recently, the notion of social capital has been brought to the fore as a potential source of economic growth. The most usual definition is from Putnam (1993), who presents social capital as the "features of social organization, such as trust, norms, and networks, that can improve the 
efficiency of society by facilitating co-ordinated actions." Several empirical studies attempt to quantify the contribution of social capital to growth. For example, Knack and Keefer (1997) establish a causal relationship between trust and growth. Temple and Johnson (1998) use an index composed of several measures of social capital, and find it a useful predictor of economic growth. Other empirical studies estimate a robust relationship between social capital and growth (e.g. Beugelsdijk et al, 2004, Rupasinga, 2000, and Whiteley, 2000), although the estimates vary widely.

A few theoretical developments have been proposed to bring social capital into economic models, namely Beugelsdijk and Smulders (2004) where social capital is modelled as participation in two distinct networks, a closed one (family and friends) and an open one that bridges across different communities. The model is tested using data from the European Values Survey and the conclusion is that higher values attached to family life reduce output growth. Nonetheless, it is most common for social capital to be modelled as an asset that contributes to production (as in Chou, 2006, and Glaeser et al, 2002). Few papers explicitly model the links between social and human capital ${ }^{1}$ and, to our knowledge, none consider social, human and natural capital, along with physical capital, in the same framework. Nonetheless, there are many empirical studies analyzing the links between economic growth, natural resource abundance, education, and institutions (see for example, Brunnschweiler and Bulte, 2008, Cole, 2007, Constantini and Monni, 2008, and Gylfason and Zoega, 2006). Pretty and Ward (2001) also present a number of case studies to support their view that social and human capital formation are linked with the improvement in natural capital in rural communities. All the empirical evidence thus indicates the need for a complete asset-based framework, along the lines presented intuitively in Pearce et al (1989), that can focus on achieving sustainable development by taking into consideration the full extent of an economy's aggregate capital stock while distinguishing its different components (see Pezzey and Toman, 2005, for a more detailed exposition of sustainability criteria ${ }^{2}$ ).

\footnotetext{
${ }^{1}$ Exceptions are Bisin and Guaitoli (2006), Chou (2006), Dinda (2007), and Sequeira and Ferreira-Lopes (2008).

${ }^{2}$ It is often important to distinguish weak sustainability, where only the value of the aggregate capital stock is held constant, and strong sustainability, where some specific capital components are seen to be crucial and irreplaceable, and thus must be maintained irrespective of other capital investment. However, this discussion is not so prominent in the context of endogenous growth models such as this one since we are looking for the existence of steady-state solutions where all capital components are, by definition, either growing or stable.
} 
In spite of serious data shortcomings, the World Bank has attempted an empirical estimation of the value of wealth for a large set of countries (World Bank, 2006). The report clearly acknowledges the above-mentioned connection between wealth and sustainability, for instance noting in the Foreword that the estimation "yields important insights into the prospects for sustainable development in countries around the world". Direct estimates are provided for produced capital and natural capital (although only some components are included), whereas intangible capital, which includes human and institutional factors, is obtained indirectly. One of the main conclusions is that the intangible component almost always accounts for the largest share of countries' wealth. This result highlights, once more, the importance of developing a theoretical framework that explicitly incorporates these components.

In this paper we present a general model of the relationships between all relevant assets, i.e. natural capital, produced capital, social capital, and human capital, in an attempt to provide an inclusive theoretical view of their potential contributions to economic growth in an endogenous growth framework. ${ }^{3}$ The goal is to contribute to the development of analytical tools that yield useful policy implications through the disparities between a decentralized market equilibrium and a social planner's solution. We identify the externalities that are present in the model, focusing on human capital, and we also calibrate it, using available empirical data, to show the distortions arising in the decentralized market economy. We conclude that the presence of an environmental asset can imply non-negligible distortions in the human capital allocations between sectors. The following section presents the model, whereas section 3.1 shows the main relationships between variables from a social planner's point of view. Section 3.2 presents the decentralized equilibrium. Section 3.3 presents the allocations of human capital and other macroeconomic variables and shows the distortions in the market solution. In section 3.4 we calibrate the model and quantify the distortions presented in the previous section, whereas section 4 concludes.

\footnotetext{
${ }^{3} \mathrm{~A}$ recent short paper by Dasgupta (2008) also uses the term inclusive wealth to denote the social value of a country's productive base.
} 


\section{Model}

In this section the several types of capital mentioned in the Introduction are modelled, along with the assumptions on their evolution. The accumulation of produced capital, $K_{P}$, arises through production that is not consumed, and is, as usual, subject to depreciation:

$$
\dot{K}_{P}=Y-C-\delta_{P} K_{P}
$$

where $Y$ denotes production of final goods, $C$ is consumption, and $\delta_{P}$ represents depreciation.

We propose that human capital $K_{H}$ is created using human capital allocated to schooling as well as the total amount of social capital, $K s$, according to:

$$
\dot{K}_{H}=\xi H_{H}+\alpha K_{S}-\delta_{H} K_{H}
$$

where $H_{H}$ are school hours, $\xi>0$ is a parameter that measures productivity inside schools, $\alpha \geq 0$ measures the sensitivity of human capital accumulation to the stock of social capital, and $\delta_{H} \geq 0$ is the depreciation of human capital. This expression echoes the writings of Coleman (1988) and Teachman et al (1997) according to which social capital is important to the production of human capital. It also indicates that human and social capital are substitutes in the production of human capital.

Human capital is an essential part of the model as it is the main driver for growth. To emphasize its many roles, we divide human capital into several components, thus indicating that the stock of knowledge and skills at any given time can be put to different uses, namely: final good production $\left(H_{Y}\right)$, school attendance $\left(H_{H}\right)$, social capital accumulation $\left(H_{S}\right)$, and environmental research or pollution prevention $\left(H_{N}\right)$. This captures the idea that not all knowledge is applied in the same way: in particular, some isn't directly relevant to the quality of the environment but some is extremely consequential (Ehrlich et al, 1999). Assuming that the different human capital activities aren't done cumulatively, we have:

$$
K_{H}=H_{Y}+H_{H}+H_{S}+H_{N}
$$

Social capital accumulation requires human capital to be allocated to its production, since social evolution (including the development of institutions and policies) requires adequate knowledge. Nonetheless, at each point in time it can also depend on the current stock of social capital, i.e.:

$$
\dot{K}_{S}=\omega H_{S}+\Omega K_{S}
$$


where $\omega$ measures the productivity of human capital in the production of social capital and $\Omega \lessgtr 0$ measures the dynamic effect of social capital on its own production. If $\Omega>0$ the existing stock of social capital is strong enough to keep growing without additional human capital. If $\Omega<0$, on the other hand, there is a net depreciation effect.

Natural capital, $K_{N}$, can be thought of as an aggregate measure of natural amenities composed of all environmental assets, including traditional natural resources, waste disposal, and environmental services. This stock variable behaves like a renewable resource, with:

$$
\dot{K}_{N}=R\left(K_{N}\right)-N_{Y}+P
$$

where $R\left(K_{N}\right)$ is the natural regeneration rate, $N_{Y}$ represents resource depletion due to its use in production, and $P$ represents the positive effects of environmental protection, so that it embodies human efforts at improving environmental quality over and above what would come from the natural rate of regeneration. Regeneration is assumed to follow a logistic function, attaining a zero value when the stock is zero and when it approaches its carrying capacity, $C C$. This rules out the unrealistic possibility of infinitely growing natural capital. A possible functional form is $R\left(K_{N}\right)=i K_{N}\left(C C-K_{N}\right)$, where $i$ is a growth parameter and $C C$ is constant (for a more complex model where carrying capacity depends on stock size, see Rodrigues et al, 2005).

As for $P$, considering the different forms it can take (abatement or clean-up actions, resource protection programs, and so on), we assume it is endogenously determined instead of being chosen by a single agent. ${ }^{4}$ In particular, $P$ is expected to depend positively on the allocation of human capital to environmental protection, which captures the idea of specific knowledge, and negatively on the stock of produced capital, since a higher $K_{P}$ implies higher material growth, making abatement more difficult. ${ }^{5}$ We also assume that improvements in social capital $\left(K_{S}\right)$ increase environmental protection, to reflect the perception that higher levels of trust or institutional quality reinforce environmental awareness. This idea is present in the empirical papers mentioned in the Introduction, in particular Cole (2007), which shows a significant, and positive, direct impact of corruption

\footnotetext{
${ }^{4}$ Economides and Phillipopoulos (2008) consider a similar environmental protection effect, although in that case the central issue is the government's cleanup policy, which depends on tax returns but has no direct relationship with the economy's assets.

${ }^{5}$ Xepapadeas (2005) presents a model where emissions increase with produced capital and decrease with abatement capital.
} 
on pollution, separate from the negative indirect one, through its impact on production (since less production implies less pollution). It is also tested by Owen and Videras (2006) and Torgler and García-Valinas (2007), which conclude that social capital (described by attitudes toward civic cooperation in the first case and by trust and political interest variables in the second) has a significant impact on pro-environmental attitudes.

Thus, environmental protection has the following expression:

$$
P=m_{0} \frac{H_{N}^{\epsilon} K_{S}^{\kappa}}{K_{P}^{\varphi}}
$$

where $m_{0}$ is a scale factor, $\varphi$ captures the elasticity of environmental deterioration with respect to physical capital, and $\epsilon$ and $\kappa$ are parameters for the impact of environmental research and social capital, respectively. Realistically, we also need to add the constraint that $R\left(K_{N}\right)>0$ in a steady state, ie. environmental protection cannot fully replace vanishing natural resources.

The production of final goods will draw upon man-made capital, direct use of natural resources, knowledge, and social capital (networks or institutions), so that all inputs are required. Assuming a Cobb-Douglas technology, each exponent is the production elasticity of the associated input. To maintain the traditional assumption that there are constant returns to scale on the typical factors (produced capital, human capital and natural resources), we use:

$$
Y=K_{P}^{\beta} N_{Y}^{\nu} H_{Y}^{\eta} K_{S}^{\sigma} \quad \beta+\nu+\eta=1
$$

Note that $K_{P}$ and $K_{S}$ fully contribute to final goods production, but only the part of natural capital that is removed from the stock variable is included. Thus, only the flows of matter that are being transformed contribute to production. ${ }^{6}$ In a similar manner, only the portion of human capital that is specifically dedicated to production is considered, since the remainder is used for different activities, as stated in equation (3).

Finally, we wish to avoid the traditional narrow view of welfare, where consumption is the only relevant factor and capital stocks are no more

\footnotetext{
${ }^{6}$ For a more complete explanation of the distinction between the role of Nature as a transformative fund and as a transformed resource flow, see Kraev (2002). However, both this reference and England (2000) emphasize complementarity of natural capital in production, unlike our model which maintains the more traditional Cobb-Douglas production function, where all factors are essential but there are substitution possibilities. An additional reference is Comolli (2006), which proposes a neoclassical two-sector model with Cobb-Douglas technology in the intermediate sector and fixed proportions in final good production but treats technical progress as exogenous.
} 
than a means to that end. Household preferences in our model specify social capital and natural capital, along with consumption, as arguments of the intertemporal utility function. Hence, welfare depends not only on consumption but also on the level of environmental quality and the level of trust or cooperation in the economy:

$$
U\left(C, K_{N}, K_{S}\right)=\frac{\tau}{\tau-1} \int_{0}^{\infty}\left(C_{t} K_{N}^{\phi} K_{S t}^{\psi}\right)^{\frac{\tau-1}{\tau}} e^{-\rho t} d t
$$

where $\tau$ is the intertemporal elasticity of substitution, $\phi$ represents the preference for Nature, $\psi$ is the preference for social capital, and $\rho$ is the utility discount rate, so that a higher $\rho$ indicates more impatient consumers. The $t$ subscripts are dropped in the remaining sections for ease of notation.

\section{Results}

\subsection{Optimal Growth}

It is clear that when assets directly provide utility, while simultaneously acting as inputs to the production function, the decentralized equilibrium will in general not maximize aggregate welfare. Thus we must solve a social planner's problem. In this section we derive the conditions associated with the maximization of (8) subject to the production function (7) as well as the transition equations for the different types of capital.

The problem gives rise to the following Hamiltonian function:

$$
\begin{aligned}
\mathcal{H}= & \frac{\tau}{\tau-1}\left(C K_{N}^{\phi} K_{S}^{\psi}\right)^{\frac{\tau-1}{\tau}}+\lambda_{P}\left[K_{P}^{\beta} K_{S}^{\sigma} N_{Y}^{\nu} H_{Y}^{\eta}-C-\delta_{P} K_{P}\right]+ \\
& +\lambda_{H}\left[\xi\left(K_{H}-H_{Y}-H_{S}-H_{N}\right)+\alpha K_{S}-\delta_{H} K_{H}\right]+\lambda_{S}\left(\omega H_{S}+\Omega K_{S}\right)+ \\
& +\lambda_{N}\left[R\left(K_{N}\right)+m_{0} \frac{H_{N}^{\epsilon} K_{S}^{\kappa}}{K_{P}^{\varphi}}-N_{Y}\right]
\end{aligned}
$$

where the $\lambda_{j}$ are the co-state variables for each stock $K_{j}$, with $j=P, H, S, N$. Considering choice variables $C, H_{Y}, H_{S}, H_{N}$, and $N_{Y}$, and equation (3), 
the first order conditions yield:

$$
\begin{aligned}
\frac{\partial U}{\partial C} & =\lambda_{P} \\
\lambda_{H} & =\lambda_{P} \frac{\eta Y}{H_{Y} \xi} \\
\lambda_{H} & =\frac{\lambda_{S} \omega}{\xi} \\
\lambda_{P} \frac{v Y}{N_{Y}} & =\lambda_{N} \\
\lambda_{H} & =\lambda_{N} \frac{m_{0} \epsilon H_{N}^{\epsilon-1} K_{S}^{\kappa}}{K_{P}^{\varphi} \xi}
\end{aligned}
$$

as well as:

$$
\begin{aligned}
\rho \lambda_{P}-\dot{\lambda}_{P} & =\lambda_{P} \frac{\beta Y}{K_{P}}-\lambda_{P} \delta_{P}-\lambda_{N} \frac{m_{0} \varphi H_{N}^{\epsilon} K_{S}^{\kappa}}{K_{P}^{\varphi+1}} \\
\frac{\dot{\lambda}_{H}}{\lambda_{H}} & =\rho+\delta_{H}-\xi \\
\rho \lambda_{S}-\dot{\lambda}_{S} & =\left(\frac{\partial U}{\partial K_{S}}+\frac{\lambda_{P} \sigma Y}{K_{S}}+\lambda_{H} \alpha+\lambda_{S} \Omega+\lambda_{N} \frac{m_{0} \kappa H_{N}^{\epsilon} K_{S}^{\kappa-1}}{K_{P}^{\varphi}}\right) \\
\rho \lambda_{N}-\dot{\lambda}_{N} & =\left(\frac{\partial U}{\partial K_{N}}+\lambda_{N} \frac{\partial R}{\partial K_{N}}\right)
\end{aligned}
$$

and the required transversality conditions. As usual, $\frac{\partial U}{\partial C}, \frac{\partial U}{\partial K_{S}}, \frac{\partial U}{\partial K_{N}}$, represent the marginal utilities of consumption, social capital, and natural capital, respectively. Also, $\frac{\partial R}{\partial K_{N}}$ is the impact of an additional unit of natural capital on its regeneration.

Conditions (10)-(14) tell us that for each control variable marginal benefits will have to be equated to marginal costs for efficiency to be achieved. For instance, condition (10) balances the marginal utility of consumption with the shadow price of produced capital (since one unit of production that is consumed is no longer available for capital accumulation); likewise, condition (11) equates the shadow price of human capital to its value in production, whereas conditions (12) and (14) equate the same shadow price (as human capital can be put to different uses) to its value in social capital accumulation and environmental protection, respectively. Finally, condition (13) balances the costs of using a unit of natural capital in production (its lost shadow value, reflecting future benefits), with its benefit in terms of production.

On the other hand, conditions (15)-(18) show the factors influencing the dynamic evolution of the shadow prices for each one of the capital 
types. Namely, condition (15) reflects that giving up a unit of $K_{P}$ yields a benefit (from the discount rate and the avoided depreciation) as well as a loss equal to the value of the marginal productivity of produced capital; condition (16) tells a similar story except the loss is in the accumulation of human capital; condition (17) shows that, for each unit of $K_{S}$ that is relinquished, the value foregone includes the direct impact on utility, the value of the marginal productivity of social capital, its contribution to both human and social capital accumulation, and its benefits on environmental protection). Finally, condition (18) highlights the value of the natural capital stock to utility as well as its role in future regeneration.

\subsubsection{Optimal Growth Rates}

At the steady state of the model, growth rates must, by definition, be constant, so equation (1) tells us that $K_{P}, Y$, and $C$ all grow at the same rate. Furthermore, $K_{S}$ and $K_{H}$ will be growing at a different rate, as will be shown below, while respecting equations (2) and (4). The growth rate of $K_{N}$ is zero in the steady-state, as it is physically impossible for natural resources to grow without bounds.

In the steady-state, we can obtain the human capital growth rate as follows. From (11) we find $\frac{\dot{\lambda}_{P}}{\lambda_{P}}=g_{K_{H}}+\frac{\dot{\lambda}_{H}}{\lambda_{H}}-g_{Y}$ and using the result from equation (16), we can then replace the previous two equations into $-\frac{1}{\tau} g_{Y}+$ $\psi\left(1-\frac{1}{\tau}\right) g_{K_{H}}=\frac{\dot{\lambda}_{P}}{\lambda_{P}}$, which we calculated from (10). The substitution yields:

$$
\left(1-\frac{1}{\tau}\right) g_{Y}+g_{K_{H}}\left(\psi\left(1-\frac{1}{\tau}\right)-1\right)=\rho+\delta_{H}-\xi
$$

To simplify the above expression, we log-differentiate equation (7), yielding:

$$
g_{Y}=g_{K_{H}}\left(\frac{\eta+\sigma}{1-\beta}\right)
$$

We can substitute the last expression in equation (19) to get the growth rate of human capital:

$$
g_{K_{H}}^{*}=\frac{\xi-\delta_{H}-\rho}{1+\left(\frac{\eta+\sigma}{1-\beta}+\psi\right)\left(\frac{1}{\tau}-1\right)}
$$

Substituting equation (21) in equation (20) we get the output growth rate:

$$
g_{Y}^{*}=\frac{\left(\xi-\delta_{H}-\rho\right)\left(\frac{\eta+\sigma}{1-\beta}\right)}{1+\left(\frac{\eta+\sigma}{1-\beta}+\psi\right)\left(\frac{1}{\tau}-1\right)}
$$


Since $1-\beta=\eta+\nu$, the growth of production (and subsequently, of consumption) may be higher or lower than the growth of human capital, depending on $\sigma \lessgtr \nu$, that is, depending on whether the productivity associated with social capital is enough to compensate for the resource drag. The larger the value of $\nu$, the more likely that $g_{Y}<g_{K_{H}}$ as expected, since a higher share of natural capital in production implies a greater effort in terms of human and social capital to keep consumption growing. It is also clear that a strong preference for social capital $(\psi)$ will reduce growth rates. This effect is due to the rival nature of human capital uses. If there is a larger investment in social capital accumulation then there will be less for other activities, namely human capital accumulation.

\subsection{Decentralized Equilibrium}

In the decentralized equilibrium both consumers and firms have choices to make. Consumers are assumed to maximize the intertemporal utility function:

$$
\frac{\tau}{\tau-1} \int_{0}^{\infty}\left(C_{t} K_{N t}^{\phi} K_{S t}^{\psi}\right)^{\frac{\tau-1}{\tau}} e^{-\rho t} d t
$$

subject to the budget constraint:

$$
\dot{a}=\left(r-\delta_{p}\right) a+W_{H} H_{Y}-C
$$

where $a$ represents the value of physical assets, $r$ is the return on physical capital, and $W_{H}$ is the market wage. The market price for the consumption good is normalized to 1 . Since it is making an intertemporal choice, the family also takes into account equations (2) and (4), which represent human and social capital accumulation, respectively. Note that, although natural capital influences utility, there is nothing in the consumer choice affecting $K_{N}$ directly, so that the consumer does not consider its evolution. This will be a source of externalities from the production to the consumption side. First order conditions for the consumer problem in the decentralized equilibrium can be found in Appendix A.

The firm maximizes profit, $\pi$ :

$$
\pi=K_{P}^{\beta} K_{S}^{\sigma} N_{Y}^{v} H_{Y}^{\eta}-W_{H} H_{Y}-r K_{P}
$$

The markets for purchased production factors are assumed to be competitive. However, the firm cannot buy social capital, as there is, in effect, no market for it. Social capital is treated here as exogenous, although 
it affects the firm's production. Hence, consumer decisions will carry social capital externalities. At this point it should be stressed that as it stands, the problem does not have a stable interior solution since there is a benefit for the firm of using natural capital (its marginal productivity, $\frac{\partial Y}{\partial N_{Y}}=\nu K_{P}^{\beta} K_{S}^{\sigma} N_{Y}^{v-1} H_{Y}^{\eta}=\frac{\nu Y}{N_{Y}}>0$ is positive and it grows as $\mathrm{Y}$ grows) but there is no cost. As is typical in these decentralized models (see for example Bovenberg and Smulders, 1995), there needs to be a mechanism to prevent total destruction of the natural capital stock. If a price (such as an emission tax) was established, it would have to keep growing to reflect the higher scarcity value of the natural resource as other capital stocks grow (see equation (18)). To find an equilibrium, we assume that there is a maximum level of natural capital, $N^{M a x}$, that the firm can use at each moment, whether due to technological constraints or to government limits (emission standards or resource use constraints such as those associated with a permit market).

From this problem we know that returns on production factors equal marginal productivities, as follows:

$$
\begin{gathered}
W_{H}=\frac{\eta Y}{H_{Y}} \\
r=\frac{\beta Y}{K_{P}}
\end{gathered}
$$

In Appendix B we have calculated the growth rates of human capital and output in the decentralized equilibrium, and they are shown to be the same as those for the optimal solution. This is a feature of semi-endogenous models of endogenous growth (Jones, 1995) and of models of endogenous growth with human capital accumulation and R\&D (e.g. Arnold, 2000). It results from the fact that in this model, long-run growth is driven by human capital accumulation and that there are no externalities directly associated with human capital stock. However, in the following section we show that there are human capital allocation distortions in the decentralized equilibrium, so the levels of variables would not coincide even if $N^{\text {Max }}=N_{Y}^{*}$.

\subsection{Distortions}

Given the importance of human capital as a driver of growth, in this section we look at the distortions that arise in human capital allocation. The shares 
of human capital allocated to the different sectors in the social planner are:

$$
\begin{aligned}
& u_{Y}^{*}=\frac{H_{Y}}{K_{H}}=\frac{\left(\xi-\delta_{H}-\frac{\omega \alpha}{\xi}-\Omega\right) \frac{K_{S}}{K_{H}}-\frac{\omega \kappa}{\epsilon} u_{N}^{*}}{\frac{\omega}{\eta}\left(\psi\left(\frac{C}{Y}\right)^{*}+\sigma\right)} \\
& u_{S}^{*}=\frac{H_{S}}{K_{H}}=\left(\frac{g_{K_{S}}^{*}-\Omega}{\omega}\right)\left(\frac{K_{S}}{K_{H}}\right)^{*} \\
& u_{H}^{*}=\frac{H_{H}}{K_{H}}=\frac{1}{\xi}\left(g_{K_{H}}^{*}+\delta_{H}\right)-\frac{\alpha}{\xi}\left(\frac{K_{S}}{K_{H}}\right)^{*} \\
& u_{N}^{*}=\frac{H_{N}}{K_{H}}=\frac{\Phi}{\frac{\eta \varphi}{\epsilon}} u_{Y}^{*}
\end{aligned}
$$

where $\Phi=\left[\beta-\frac{\rho+\delta_{P}+g_{Y}\left[\frac{1}{\tau}-\psi\left(1-\frac{1}{\tau}\right)\left(\frac{1-\beta}{\sigma+\eta}\right)\right]}{\frac{g_{Y}+\delta_{P}}{\left(1-\left(\frac{C}{Y}\right)^{*}\right)}}\right]$, and an expression for $\left(\frac{C}{Y}\right)^{*}$ is given in Appendix $\mathrm{C}$. The equations that are presented in this section provide a basis for a complete analysis of all the relationships between the different capital stocks and also a basis for the comparison with the decentralized equilibrium solution. All derivations are in Appendix D.

Using the restriction that $u_{Y}^{*}+u_{S}^{*}+u_{H}^{*}+u_{N}^{*}=1$, we obtain the social to human capital ratio that the social planner would choose:

$$
\left(\frac{K_{S}}{K_{H}}\right)^{*}=\frac{1-\frac{1}{\xi}\left(g_{K_{H}}^{*}+\delta_{H}\right)}{\frac{\left(\xi-\delta_{H}-\frac{\omega \alpha}{\xi}-\Omega\right)}{\frac{\omega}{\eta}\left(\psi\left(\frac{C}{Y}\right)^{*}+\sigma\right)+\omega \kappa \frac{\Phi}{\eta \varphi}}+\left(\frac{g_{K_{S}}^{*}-\Omega}{\omega}\right)-\frac{\alpha}{\xi}}
$$

The shares of human capital allocated to the different sectors in the decentralized equilibrium are:

$$
\begin{aligned}
u_{Y}^{D E} & =\frac{H_{Y}}{K_{H}}=\frac{\xi-\delta_{H}-\frac{\omega \gamma}{\xi}-\Omega}{\frac{\omega}{\eta}\left[\psi\left(\frac{C}{Y}\right)^{D E}\right]}\left(\frac{K_{S}}{K_{H}}\right)^{D E} \\
u_{S}^{D E} & =\frac{H_{S}}{K_{H}}=\left(\frac{g_{K_{S}}^{D E}-\Omega}{\omega}\right)\left(\frac{K_{S}}{K_{H}}\right)^{D E} \\
u_{H}^{D E} & =\frac{H_{H}}{K_{H}}=\frac{1}{\xi}\left(g_{K_{H}}^{D E}+\delta_{H}\right)-\frac{\alpha}{\xi}\left(\frac{K_{S}}{K_{H}}\right)^{D E} \\
u_{N}^{D E} & =\frac{H_{N}}{K_{H}}=0
\end{aligned}
$$

where an expression for $\left(\frac{C}{Y}\right)^{D E}$ is also given in Appendix C. Again, we obtain the decentralized equilibrium's social to human capital ratio:

$$
\left(\frac{K_{S}}{K_{H}}\right)^{D E}=\frac{1-\frac{1}{\xi}\left(g_{K_{H}}^{D E}+\delta_{H}\right)}{\frac{\xi-\delta_{H}-\frac{\omega \gamma}{\xi}-\Omega}{\frac{\omega}{\eta}\left[\psi\left(\frac{C}{Y}\right)^{D E}\right]}+\frac{g_{K_{S}}^{D E}-\Omega}{\omega}-\frac{\alpha}{\xi}}
$$


As mentioned above, growth rates are equal in the decentralized equilibrium and in the optimal solution, so that the differences between the two solutions are given by the following externalities:

- The environmental externality: this externality has two different sources. There is a direct source, linked with the value of the natural environment in the utility function, which is not considered in the human capital allocation decisions of firms in the market solution, so that $u_{N}^{*}>0=u_{N}^{D E}$. Then there is an indirect source, linked with the effect that physical capital has on environmental protection, affecting the consumption-output ratio, which is lower in the optimal solution than in the decentralized equilibrium. This indirect effect pulls in the direction of overinvestment in social capital relative to human capital. It also means that the market economy is saving less than the optimal level, which is a new result in this type of models, where the market saving rate tends to be optimal.

- The social capital externality. This externality also arises from two sources. As there is no market for social capital, the social planner would invest more in it than is warranted in the decentralized equilibrium. This happens because in the latter the positive effect of social capital on production $(\sigma>0)$ is not internalized. From this, in the market equilibrium one would tend to encounter lower human capital allocation to social capital buildup and to final good production, although there would be a higher allocation to human capital accumulation when compared to optimal allocations. This externality acts in opposition to the environment externality, since when pushing $u_{S}^{*}$ up, the social planner faces a trade-off with his desire to increase $u_{N}^{*}$ as well.

- The social-natural capital externality. There is another source of externalities through the link between social and natural capital regeneration $(\kappa>0)$. The social planner will again desire more social capital than the decentralized agents, since social capital increases environmental protection, which is a valuable effect from the social planner's point of view.

One of the goals of this analysis is to determine the optimal allocation of human capital through sectors of activity and what should be done in order to bring it to optimal values. From what has been discussed above, 
intervention policies should always focus on increasing the human capital dedicated to environmental protection (through the financing of "green jobs" or R\&D in the environmental sector), whereas the optimal mix of other human capital allocations depends on parameter values, as shown in section 3.4 .

A final point can be made regarding the amount of natural capital that is appropriated for production. While in the decentralized equilibrium there needs to be a maximum level of natural capital, $N^{M a x}$, that the firm can use at each moment, in the social planner solution there is an optimal level of resource use. In fact, from equations (11), (13) and (14) we get $N_{Y}^{*}=\frac{\nu H_{Y} m_{0} \epsilon H_{N}^{\epsilon-1} K_{S}^{\kappa}}{\eta K_{P}^{\varphi}}$, which can be simplified to $N_{Y}^{*}=\frac{u_{Y}}{u_{N}} \frac{\nu \epsilon}{\eta} P$, so that the optimal resource use is proportional to the level of environmental protection (note that $\frac{u_{Y}}{u_{N}} \frac{\nu \epsilon}{\eta}>1$ for $R\left(K_{N}\right)>0$ ). Thus, more extraction could be allowed the higher the relative allocation of human capital to final good production, the higher the relative productivity of $N_{Y}$ compared to that of $H_{Y}$, and the higher the impact of specific human capital on environmental protection.

The results obtained thus far can be summarized as follows.

Result 1 The decentralized economy saves, as a percentage of income, less than the social planner would (and hence consumes more), because the social planner wants to save more resources for the future and spend less in the present, as a means to protect the environment.

Result 2 The social planner would allocate human capital to environmental protection, while the decentralized economy would not. Specific sectors to which the social planner allocates less human capital than the decentralized economy depend on the specific parameter values.

Result 3 The decentralized equilibrium requires the setting of a maximum level of natural capital use to avoid resource collapse, whereas in the optimal solution the level of resource use would be proportional to environmental protection.

\subsection{Model Calibration}

\subsubsection{Parameter Calibration}

In this section, we present and justify the calibrated values for parameters. We use three main sets of parameter values: the first set is chosen to fit 
the whole world, the second fits Europe and Central Asia and the last is for Low Income Countries (mostly African and Latin American countries). Most parameters come from the report "Where is the Wealth of Nations?" (World Bank, 2006). This reference has values for the shares of produced capital, intangible capital, and natural capital in total wealth for different regions in the world, which correspond in the model to values for parameters $\beta, \nu$, and $\eta+\sigma$. The share of social capital has to be disentangled from intangible capital. For that, we use the fact that a level of trust that is 10 p.p. higher has been associated with an annual growth rate that is higher by 0.8 p.p. (Knack and Keefer, 1997), thus $\sigma=0.08$.

For each parameter set, we use per capita GDP average growth rates between 1973 and 2001 for the specific regions considered, from Maddison (2003). These are $1.41 \%$ for the World, $1.28 \%$ for Europe and Central Asia, and $0.55 \%$ for Low Income Countries (which is an average between the growth rates for Africa and Latin America in the period). For the elasticity of intertemporal substitution $(\tau)$ we follow Jones at al (2000) in considering $\tau=0.8$. This is an important parameter, so it's worth noting that a value in this range is also empirically supported (see Guvenen, 2006). For the consumption-output ratio, we consider values from the World Development Network Database (World Bank, 2001) on gross savings rates to calculate averages for the World, for Europe and Central Asia, and for Low Income Countries.

The crucial parameter that measures productivity of education allocation to the education sector $(\xi)$ is set according to the economic growth rate of human capital. ${ }^{7}$ The discount rate is set to 0.01 , a value in the range used in the literature. The same value is used for the depreciation rate of produced capital, at the lower bound of the interval usually found in the literature. It is usual to see endogenous growth models with human capital accumulation considering no depreciation of human capital, thus we also set $\delta_{H}=0$. There are no empirical references that can easily guide the calibrations of parameters that rule the mutual influences of social capital on and from human capital. Thus, we consider $\omega=\alpha=0.01$. We also consider that $\Omega=0.01$ (allowing for exogenous social capital growth) and we set the weight of social capital in utility is $\psi=0.2$ (allowing for a lower weight than that of consumer) and We have performed a sensitivity analysis on the parameter values presented in this paragraph and there are

$$
{ }^{7} \xi=\left[\left(\frac{\eta+\sigma}{1-\beta}+\psi\right)\left(\frac{1}{\tau}-1\right)+1\right] g_{Y}+\rho+\delta_{H} .
$$


no significant changes in the results. Some other parameters do have a stronger influence and we summarize significant results in section 3.4.3.

To calibrate the parameter that estimates the relationship between physical capital and environmental protection $(\varphi)$, we note that the growth rate of produced capital is equal to the per capita output growth rate, and thus we refer to the discussion on the Environmental Kuznets Curve (EKC). This predicts an inverted U-shaped relationship between the level of income and pollution (which is an inverted function of environmental protection). However, recently, specific country studies have noted that the relationship between income and pollutants can be almost linear or, for some pollutants, N-shaped. For example, from Roca et al. (2001) we see that the EKC is rejected for Spain and the effect of income on pollution is near 1.2. From Akbostanci et al.(2009), we learn that this coefficient for Turkey is about 3.5. From Song et al. (2008), we find coefficients from 1.5 to 3, in a work applied to China. Given this evidence we choose a parameter $\varphi=2$ for the World, $\varphi=1.2$ when applied to Europe, and $\varphi=3$ when applied to Low Income Countries. For the influence of human capital in environmental protection $(\epsilon)$, we adopted the value of 1 . For the value of natural resources in utility, we have adopted the mean value of $\phi=0.35$ from Economides and Phillipopoulos (2008). Finally, for $\kappa$, we use the fact that $P$ must be constant at the steady-state and thus $\kappa=\varphi \frac{1+\sigma}{\eta+\beta}-\epsilon$. The next tables summarize the calibration values for the three different scenarios we will work with.

\author{
[Insert Table 1] \\ [Insert Table 2] \\ [Insert Table 3]
}

\title{
3.4.2 Quantifying Distortions
}

In this section, we present the main economic indicators for the social planner solution and for the decentralized equilibrium, for the different exercises we have described above. Table 4 shows the results.

[Insert Table 4] 
As expected, the social capital to human capital ratio is always suboptimal and the consumption output ratio is always above the optimal level for that ratio An analysis of the allocation of human capital between its different uses shows that, as expected, the allocation of human capital to environmental protection is only done in the optimal choice. Moreover, the under-optimal ratio of social to human capital directly implies an underoptimal allocation to the social capital sector. Usually, in the calibrations for the World and for Europe and Central Asia, the decentralized economy allocated more human capital to the final good than desired from the social planner's point of view. However, this is inverted in the Low Income Countries calibration. Finally, allocation of human capital to school attendance is always above the optimal level. The social planner increases the allocation of human capital to social capital accumulation and environmental protection due to the two types of externalities explained above.

\subsubsection{Sensitivity Analysis}

As a first sensitivity analysis, we eliminate the externality due to the social capital market failure $(\sigma=0)$. We note that all the distortions described above still appear, although the distortion in the allocation of human capital to the social capital sector decreases. However, the social-natural capital externality $(\kappa>0)$ is sufficiently strong to keep market investment in social capital below the optimal level. When setting $\kappa=0$ the results change. Here we only present results for Low Income Countries, as it is the experiment where the distortions are bigger. Nonetheless, the direction of distortions are equal in the other calibrations.

\section{[Insert Table 5]}

Table 5 shows that without the externalities caused by social capital, its decentralized allocation is above the optimal level, whereas human capital allocation to school attendance becomes lower than the optimal level. In this case, policies leading to a steady state would do well to invest more in general human capital accumulation. Also note that, contrary to what happened in Table 4, this exercise shows overallocation of resources to the final good.

In previous models without social or natural capital (e.g. Reis and Sequeira, 2007), there were no distortions that actually affected the human 
capital allocation to school attendance, in spite of the consideration of externalities from R\&D. In this model, it is the participation of social capital in human capital accumulation that induces such distortions. If we set $\alpha=0$, we recover that result.

\section{Conclusion}

Achieving economic growth has always been a major concern of economic theory and policy. Several significant developments have appeared in the literature, especially in the last two decades. In particular, human capital has been included beside produced capital as an essential force for growth, and the role of natural capital has been discussed thoroughly. More recently, attention has been drawn to the notion of social capital, seen as the level of trust, social norms, and social networking, as an additional explanatory factor for growth. Nonetheless, existing models typically include only two or, rarely, three types of capital, so that at best they can provide a partial view of the growth trends.

In this paper we propose an intertemporally efficient model containing the four categories of assets that can be defined, namely produced capital, natural capital, human capital, and social capital, in an attempt to emphasize the relationships between them in an inclusive model of sustainable growth. We propose a direct link between human and social capital, and we also add an environmental protection function which summarizes the expected impacts of different capital stocks on natural capital evolution. Considering the specificities associated with each type of capital, we identify several plausible externalities connected with social and natural capital. Namely, there are two types of externalities linked with social capital. First, there is a market failure for social capital, as social capital contributes to production but firms do not pay for it, so a social planner would produce more social capital than the amount produced in the market. Second, social capital increases environmental protection (or decreases pollution), an effect that is not internalized by the market. Furthermore, the presence of natural capital also brings about two different externalities. On the one hand, in the decentralized setup there is no incentive to allocate human capital to environmental protection. On the other hand, the effect of produced capital in environmental protection is not internalized in the decentralized economy. Contrary to typical results in models of endogenous growth without natural resources, this externality implies distortions 
in the output to capital ratio and in the consumption to output ratio, with a higher savings rate under the social planner framework. Moreover, we note that, due to all these externalities, the social planner will choose to allocate more human capital to environmental protection and social capital accumulation, thus tending to an allocation of less human capital to final good production and to school attendance. Even if our model does not explicitly model government decisions, it does point to some policy implications, namely the likely need for a limit to resource use and the correction of human capital allocations so as to increase knowledge available for environmental protection and social capital accumulation. The analysis of government interventions to correct steady-state distortions and to ensure proper transition paths is an area for further research.

Future efforts can also be focused on studying alternative formulations for each capital type and the connections between them, as these can bring significant changes to traditional growth model results. Finally, we note that work on inclusive sustainable growth should also be undertaken for models where uncertainty exists, in particularly when systems are complex and unstable. System resilience is turning out to be a key property in the search for sustainability and its consideration should be sought in discussions about economic growth in the real, natural world.

\section{Acknowledgements}

The authors thank participants at the $2^{\text {nd }}$ Annual Meeting of the Portuguese Economic Journal, at the XVI Conference of the European Association of Environmental and Resource Economists (EAERE), as well as participants at the seminars at Instituto Superior de Economia e Gestão (ISEG-UTL), and Fundación de Estudios de Economia Aplicada (FEDEA), for helpful comments and discussions.

\section{References}

[1] Aghion, P., Howitt, P., 1998. Endogenous Growth Theory, MIT Press, Cambridge, MA, ch.5.

[2] Akbostanci, E, Serap, T., Tunç, G., 2009. The Relationship Between Income and Environment in Turkey: Is There an Environmental Kuznets Curve? Energy Policy 37, 861-867. 
[3] Arnold, L., 2000. Endogenous growth with physical capital, human capital and product variety: A Comment. European Economic Review 44, 1599-1605.

[4] Bartolini, S., Bonatti, L., 2007. Endogenous Growth, Decline in Social Capital and Expansion of Market Activities. MPRA Working-Paper 3341.

[5] Beugelsdijk, S., Groot, H., van Schaik, A., 2004. Trust and Economic Growth: A Robustness Analysis. Oxford Economic Papers 56, 118-134.

[6] Beugelsdijk, S., Smulders, S., 2009. Bonding and Bridging Social Capital and Economic. GrowthCentER discussion paper 2009-27.

[7] Bisin, B., Guaitoli, D., 2006. Social Capital, Modernization and Growth. ASSET Conference 2006, mimeo.

[8] Bovenberg, L., Smulders, S., 1995. Environmental Quality and Pollution-Augmenting Technological Change in a Two-Sector Endogenous Growth Model. Journal of Public Economics 57, 369-391.

[9] Brunnschweiler, C., Bulte, E., 2008. The resource curse revisited and revised: a tale of paradoxes and red herrings. Journal of Environmental Economics and Management 55, 248-264.

[10] Chou, Y.K., 2006. Three simple models of social capital and economic growth. The Journal of Socio-Economics 35, 889-912.

[11] Cole, M., 2007. Corruption, income and the environment: An empirical analysis. Ecological Economics 62, 637-647.

[12] Coleman, J., 1988. Social Capital in the Creation of Human Capital. American Journal of Sociology 94, S95-S120.

[13] Comolli, P., 2006.Sustainability and growth when manufactured capital and natural capital are not substitutable. Ecological Economics 60, $157-167$.

[14] Constantini, V., Monni, S., 2008. Environment, Human Development and Economic Growth. Ecological Economics 64, 867-880.

[15] Dasgupta, P., Heal, G., 1979. Economic Theory and Exhaustible Resources, Cambridge University Press, Cambridge. 
[16] Dasgupta, P., 2008. Nature in Economics. Environmental and Resource Economics 39, 1-7.

[17] Dinda, S., 2007. Social Capital in the Creation of Human Capital and Economic Growth: a Productive Consumption Approach. The Journal of Socio-Economics, doi:10.1016/jsocec.2007.06.014.

[18] Economides, G., Phillipopoulos, A., 2008. Growth Enhancing Policy is the Means to Sustain the Environment. Review of Economic Dynamics 11, 207-219.

[19] Ehrlich, P., Wolff, G., Daily, G., Hughes, J., Daily, S., Dalton, M., Goulder, L., 1999. Knowledge and the Environment. Ecological Economics 30, 267-284.

[20] England, R., 2000. Natural Capital and the Theory of Economic Growth. Ecological Economics 34, 425-431.

[21] Glaeser, E.L., Laibson, D., Sacerdote, B., 2002. An Economic Approach to Social Capital. Economic Journal 112, F437-F458.

[22] Guvenen, M., 2006. Reconciling Conflicting Evidence on the Elasticity of Intertemporal Substitution: A Macroeconomic Perspective. Journal of Monetary Economics 537, 1451-1472.

[23] Gylfason, T., Zoega, G., 2006. Natural Resources and Economic Growth: The Role of Investment. The World Economy, 1091-1115.

[24] Heal, G., 1998. Valuing the Future: Economic Theory and Sustainability, Columbia University Press, New York.

[25] Jones, C., 1995. R\&D-based models of endogenous growth. Journal of Political Economy 103, 759-584.

[26] Jones, L., Manuelli, R., Siu, H., 2000. Growth and Business Cycles. NBER Working Paper No.7633, National Bureau of Economic Research.

[27] Knack, S., Keefer, P., 1997. Does Social Capital Have an Economic Payoff? A Cross-Country Investigation. Quarterly Journal of Economics 112, 1251-88. 
[28] Kraev, E., 2002. Stocks, Flows and Complementarity: Formalizing a Basic Insight of Ecological Economics. Ecological Economics 43, 277286.

[29] Maddison, A., 2003. The World Economy: Historical Statistics, OECD.

[30] Owen, A., Videras, J., 2006. Civic cooperation, pro-environment attitudes, and behavioural intentions. Ecological Economics 58, 814-829.

[31] Pearce, D., Markandya, A., Barbier, E., 1989. Blueprint for a Green Economy, Earthscan.

[32] Pezzey. J., Toman, M., 2005. Sustainability and its Economic Interpretations, in: Simpson, R.D., Toman, M.A., Ayres, R. (Eds.), Scarcity and Growth Revisited - Natural Resources and the Environment in the New Millenium, Resources for the Future, Washington DC.

[33] Pretty, J., Ward, H., 2001. Social Capital and the Environment. World Development 29, 209-227.

[34] Putman, R., 1993. Making Democracy Work: Civic Traditions in Modern Italy, Princeton, Princeton University Press.

[35] Reis, A., Sequeira, T., 2007. Human Capital and Overinvestment in R\&D. Scandinavian Journal of Economics 1093, 573-591.

[36] Roca, J., Padilla, E., Farré, M., Galletto, V., 2001. Economic Growth and Atmospheric Pollution in Spain: Discussing the Environmental Kuznets Curve Hypothesis. Ecological Economics 39, 85-99.

[37] Rodrigues, J., Domingos, T., Conceição, P., Belbute, J., 2005. Constraints on Dematerialisation and Allocation of Natural Capital Along a Sustainable Growth Path. Ecological Economics 54, 382-396.

[38] Rupasinga A., 2000. Social Capital and Economic Growth: A CountyLevel Analysis. Journal of Agricultural and Applied Economics 323, $565-72$.

[39] Sequeira, T.N., Ferreira-Lopes, A., 2007. An Endogenous Growth Model with Human and Social Capital Interactions. Working-Paper 08/09, Economics Research Center, Lisbon University Institute. 
[40] Song, T., Zheng, T., Tong, L., 2008. An Empirical Test of the Environmental Kuznets Curve in China: A Panel Cointegration Approach. China Economic Review 19, 381-392.

[41] Smulders, S., 2005. Endogenous Technological Change, Natural Resources, and Growth, in: Simpson, R.D., Toman, M.A., Ayres, R. (Eds.), Scarcity and Growth Revisited - Natural Resources and the Environment in the New Millenium, Resources for the Future, Washington DC.

[42] Teachman, J. D., Paasch, K., Carver, K., 1997. Social Capital and the Generation of Human Capital. Social Forces 754, 1343-1359.

[43] Temple, J., Johnson, P.A., 1998. Social Capability and Economic Growth. The Quarterly Journal of Economics 1133, 965-990.

[44] Torgler, B., García-Valinas, M. A., 2007. The determinants of individuals' attitudes towards preventing environmental damage. Ecological Economics 63, 536-552.

[45] Whiteley, P., 2000. Economic Growth and Social Capital. Political Studies 483, 443-466.

[46] World Bank, 2001. Global Development Network Growth - Macro Time Series. New York University Development Research Institute.

[47] World Bank, 2006. Where is the Wealth of Nations? Measuring Capital for the $21^{\text {st }}$ Century. The World Bank, Washington DC.

[48] Xepapadeas, A., 2005. Economic growth and the environment, in: K. G. Mäler, Vincent, J. R. (Eds.), Handbook of Environmental Economics, vol. 3, ch. 23, pages 1219-1271, Elsevier.

\section{A First Order Conditions for the Decentral- ized Equilibrium}

The choice variables for the consumers are $C, H_{H}$, and $H_{S}$, so the first order conditions for the consumer problem yield:

$$
\frac{\partial U}{\partial C}=\lambda_{a}
$$




$$
\begin{aligned}
\lambda_{H}^{\prime} & =\frac{\lambda_{a} W_{H}}{\xi} \\
\lambda_{S}^{\prime} & =\frac{\lambda_{a} W_{H}}{\omega}
\end{aligned}
$$

as well as:

$$
\begin{gathered}
\frac{\dot{\lambda}_{a}}{\lambda_{a}}=\rho+\delta_{P}-r \\
\dot{\lambda}_{H}^{\prime}=\rho \lambda_{H}^{\prime}-\left(\lambda_{a} W_{H}-\lambda_{H}^{\prime} \delta_{H}\right) \\
\dot{\lambda}_{S}^{\prime}=\rho \lambda_{S}^{\prime}-\left(\frac{\partial U}{\partial K_{S}}+\lambda_{H}^{\prime} \alpha+\lambda_{S}^{\prime} \Omega\right)
\end{gathered}
$$

where $\lambda_{a}$ is the co-state variable for the budget constraint, and $\lambda_{H}^{\prime}$ and $\lambda_{S}^{\prime}$ are co-state variables for the stocks of human and social capital, respectively.

\section{B Growth Rates in the Decentralized Equi- librium}

In the steady-state we can obtain the human capital growth rate of the decentralized equilibrium as follows. By using equation (A.5) and replacing it in $\frac{\dot{\lambda}_{H}^{\prime}}{\lambda_{H}^{\prime}}=\frac{\dot{\lambda}_{a}}{\lambda_{a}}+g_{W}$, which we get by (A.2), we find $\frac{\dot{\lambda}_{a}}{\lambda_{a}}=\rho+\delta_{H}-\xi-g_{W}$. After log-differentiating equation (25) we get $g_{W}=g_{Y}-g_{K_{H}}$. Substituting this last equation in the previous one and introducing both in $-\frac{1}{\tau} g_{Y}+$ $\psi\left(1-\frac{1}{\tau}\right) g_{K_{H}}=\frac{\dot{\lambda}_{a}}{\lambda a}$, which we calculated from (A.1), we get:

$$
\left(1-\frac{1}{\tau}\right) g_{Y}+g_{K_{H}}\left(\psi\left(1-\frac{1}{\tau}\right)-1\right)=\rho+\delta_{H}-\xi
$$

By log-differentiating the production function (7) we get:

$$
g_{Y}=g_{K_{H}}\left(\frac{\eta+\sigma}{1-\beta}\right)
$$

Substituting this last expression into (B.1) we get:

$$
g_{K_{H}}^{D E}=\frac{\xi-\delta_{H}-\rho}{\left(\frac{\eta+\sigma}{1-\beta}+\psi\right)\left(\frac{1}{\tau}-1\right)+1}
$$

By substituting equation (B.3) into (B.2) we find: 


$$
g_{Y}^{D E}=\frac{\left(\xi-\delta_{H}-\rho\right)\left(\frac{\eta+\sigma}{1-\beta}\right)}{\left(\frac{\eta+\sigma}{1-\beta}+\psi\right)\left(\frac{1}{\tau}-1\right)+1}
$$

These growth rates are equal to the ones that we found in the social planner problem, as discussed in the main text.

\section{Consumption-Output Ratios}

Now we also demonstrate the relationship between the consumption to output ratio in the decentralized equilibrium and in the social planner solution. We use this expression in the calibration of the model.

From equation (1) we get:

$$
\frac{\dot{K}_{P}}{K_{P}}=\frac{Y}{K_{P}}-\frac{C}{K_{P}}-\delta_{P}
$$

Also, from this equation we get $g_{K_{P}}=g_{Y}=g_{C}$ because the growth rates have to be constant in steady state. Since we have shown that $\left(g_{K_{P}}=g_{Y}=g_{C}\right)^{*}=\left(g_{K_{P}}=g_{Y}=g_{C}\right)^{D E}$ the left hand-side of equation (C.1) is equal in the social planner and in the decentralized equilibrium and $\delta_{P}$ is a constant.

In the social planner problem by transforming equation (10) we obtain - $\frac{\dot{\lambda}_{P}}{\lambda_{P}}=-\frac{1}{\tau} g_{C}+\psi\left(1-\frac{1}{\tau}\right) g_{K_{S}}$. Replacing this last equation in equation (15) we get:

$$
\frac{\beta Y^{*}}{K_{P}}=\frac{\rho+\delta_{P}+\frac{1}{\tau} g_{C}-\psi\left(1-\frac{1}{\tau}\right) g_{K_{S}}}{\left(1-\frac{\eta \varphi}{\epsilon \beta} \frac{u_{N}^{*}}{u_{Y}^{*}}\right)}
$$

Since we have shown that $g_{K_{P}}^{*}=g_{K_{P}}^{D E}$, hence $\left(\frac{Y}{K_{P}}-\frac{C}{K_{P}}\right)^{*}=\left(\frac{Y}{K_{P}}-\frac{C}{K_{P}}\right)^{D E}$. Using the fact that $\frac{C}{K_{P}}$ can be written as $\frac{C}{Y} \frac{Y}{K_{P}}$ and putting $\frac{Y}{K_{P}}$ in evidence, we obtain:

$$
\left(\frac{Y}{K_{P}}\right)^{*}\left(1-\frac{C}{Y}\right)^{*}=\left(\frac{Y}{K_{P}}\right)^{D E}\left(1-\frac{C}{Y}\right)^{D E}
$$

From the decentralized equilibrium, using (26) we note that $\left(\frac{\beta Y}{K_{P}}\right)^{D E}=$ $r$ and that $r=P m g_{K}$, thus:

$$
\left(\frac{\beta Y}{K_{P}}\right)^{D E}=\rho+\delta_{P}+\frac{1}{\tau} g_{C}-\psi\left(1-\frac{1}{\tau}\right) g_{K_{S}}
$$


Hence

$$
{\frac{\beta Y}{K_{P}}}^{*}=\frac{\left(\frac{\beta Y}{K_{P}}\right)^{D E}}{\left(1-\frac{\eta \varphi}{\epsilon \beta} \frac{u_{N}^{*}}{u_{Y}^{*}}\right)}
$$

Now substituting (C.5) into (C.3), we get:

$$
\left(\frac{C}{Y}\right)^{*}=\left(\frac{C}{Y}\right)^{D E}\left[1-\frac{\eta \varphi}{\epsilon \beta} \frac{u_{N}^{*}}{u_{Y}^{*}}\right]-\frac{\eta \varphi}{\epsilon \beta} \frac{u_{N}^{*}}{u_{Y}^{*}}
$$

From this equation it becomes clear that $\left(\frac{C}{Y}\right)^{*} \neq\left(\frac{C}{Y}\right)^{D E}$, because $u_{N}^{*} \neq$ 0 , and also that $\left(\frac{C}{Y}\right)^{*}<\left(\frac{C}{Y}\right)^{D E}$. We can use (27) and (30) to determine the value of $\left(\frac{C}{Y}\right)$ in the optimal solution dependent on known values:

$$
\left(\frac{C}{Y}\right)^{*}=\frac{\left(\frac{C}{Y}\right)^{D E}-\beta\left(1+\left(\frac{C}{Y}\right)^{D E}\right)+\frac{1+\left(\frac{C}{Y}\right)^{D E}(\Psi)}{g_{Y}+\delta_{P}}}{1+\frac{1+\left(\frac{C}{Y}\right)^{D E}(\Psi)}{g_{Y}+\delta_{P}}}
$$

where $\Psi=\rho+\delta_{P}+g_{Y}\left[\frac{1}{\tau}-\psi\left(1-\frac{1}{\tau}\right)\left(\frac{1-\beta}{\sigma+\eta}\right)\right]$.

\section{Human Capital Shares}

\section{D.1 Social Planner}

To obtain the share of human capital allocated to production in the social planner, we first use equation (12) which gives us: $\lambda_{H}=\frac{\lambda_{S} \omega}{\xi}$ and by substituting this expression into equation (11) we get:

$$
\lambda_{P}=\frac{H_{Y} \lambda_{S} \omega}{\eta Y}
$$

We know that $\frac{\partial U}{\partial C}=\lambda_{P}$ by equation (10) and we also know that $\frac{\partial U}{\partial K_{S}}=$ $\psi \frac{\partial U}{\partial C} \frac{C}{K_{S}}$, hence $\frac{\partial U}{\partial K_{S}}=\psi \lambda_{P} \frac{C}{K_{S}}$. Substituting (D.1.1) in this last expression we get:

$$
\frac{\partial U}{\partial K_{S}}=\psi \frac{H_{Y} \lambda_{S} \omega}{\eta Y} \frac{C}{K_{S}}
$$

Substituting equation (12) into equation (14) we obtain:

$$
\lambda_{N}=\frac{\lambda_{S} \omega K_{P}^{\varphi}}{m_{0} \epsilon H_{N}^{\epsilon-1} K_{S}^{\kappa}}
$$

By equation (12) we get that $\frac{\dot{\lambda}_{H}}{\lambda_{H}}=\frac{\dot{\lambda}_{S}}{\lambda_{S}}$, which by equation (16) is equal to $\rho+\delta_{H}-\xi$. After substituting this last expression and also (D.1.2) and 
(D.1.3) into equation (17) and dividing the referred equation by $\lambda_{S}$ we finally obtain (27).

The share of human capital allocated to environmental protection by the social planner is calculated as described next. First, we substitute equation (14) into equation (11) to get:

$$
\lambda_{N}=\frac{\lambda_{P} Y \eta K_{P}^{\varphi}}{H_{Y} m_{0} \epsilon H_{N}^{\epsilon-1} K_{S}^{\kappa}}
$$

By substituting (D.1.4) into (15) and dividing this last equation by $\lambda_{P}$ we obtain:

$$
\frac{\dot{\lambda}_{P}}{\lambda_{P}}=\rho+\delta_{P}-\frac{Y}{K_{P}}\left(\beta-\frac{\eta \varphi}{\epsilon} \frac{u_{N}}{u_{Y}}\right)
$$

Secondly, we log-differentiate equation (1) to get:

$$
\frac{Y}{K_{P}}=\frac{g_{Y}+\delta_{P}}{1-\frac{C}{Y}}
$$

Thirdly, log-differentiating equation (10) and using (20) gives us:

$$
g_{Y}\left(-\frac{1}{\tau}+\psi\left(1-\frac{1}{\tau}\right)\left(\frac{1-\beta}{\sigma+\eta}\right)\right)=\frac{\dot{\lambda}_{P}}{\lambda_{P}}
$$

Finally, substituting (D.1.6) and (D.1.7) into (D.1.5) we get (30).

We get the share of human capital allocated to school time (29) from equation (2) and the share of human capital allocated to investing in social capital (28) from equation (4).

\section{D.2 Decentralized Equilibrium}

To obtain the share of human capital allocated to production in the decentralized equilibrium, we first use equation (A.3) which gives us:

$$
\lambda_{a}=\frac{\lambda_{S}^{\prime} \omega}{W_{H}}
$$

We know that $\frac{\partial U}{\partial C}=\lambda_{a}$ by (A.1) and we also know that $\frac{\partial U}{\partial K_{S}}=\psi \frac{\partial U}{\partial C} \frac{C}{K_{S}}$, hence $\frac{\partial U}{\partial K_{S}}=\psi \lambda_{a} \frac{C}{K_{S}}$. Substituting (D.2.1) in this last expression we get:

$$
\frac{\partial U}{\partial K_{S}}=\psi \frac{\lambda_{S}^{\prime} \omega}{W_{H}} \frac{C}{K_{S}}
$$

By the substitution of (A.2) into (A.3) and by log-differentiating we get that $\frac{\dot{\lambda}_{H}^{\prime}}{\lambda_{H}^{\prime}}=\frac{\dot{\lambda}_{S}^{\prime}}{\lambda_{S}^{\prime}}$, which by equation (A.5) is equal to $\rho+\delta_{H}-\xi$. After 
substituting this last expression and also (D.2.2) into equation (A.6) and dividing this equation by $\lambda_{S}^{\prime}$ we get:

$$
\xi-\delta_{H}-\frac{\omega \gamma}{\xi}-\Omega=\psi \frac{\omega}{W_{H}} \frac{C}{K_{S}}
$$

We know by (25) that $W_{H}=\frac{\eta Y}{H_{Y}}$ and after substituting this expression into (D.2.3) we get the expression for the share of human capital allocated to production as in (32).

The share of human capital allocated to school time (34) and the share of human capital allocated to investing in social capital (33) are equal and they are obtained in the same way as in the social planner's problem. In the decentralized equilibrium the share of human capital allocated to pollution prevention (35) is zero. 


\section{TABLES}

Table 1 - Parameters Values - World

\begin{tabular}{llllllll}
\hline \multicolumn{7}{c}{ Production and Utility } \\
\hline$g_{Y}$ & $\beta$ & $\delta_{P}$ & $\tau$ & $\rho$ & $C / Y^{D E}$ \\
\hline 0.141 & 0.18 & 0.01 & 0.8 & 0.01 & 0.89 & & \\
\hline \multicolumn{7}{c}{ Social and Human Capital } \\
\hline$\xi$ & $\delta_{H}$ & $\alpha$ & $\omega$ & $\Omega$ & $\psi$ & $\sigma$ & $\eta$ \\
\hline 0.042 & 0 & 0.01 & 0.01 & 0.01 & 0.2 & 0.08 & 0.7 \\
\hline \multicolumn{7}{c}{ Natural Capital } \\
\hline$\varphi$ & $\epsilon$ & $\kappa$ & $\nu$ & $\phi$ & & \\
\hline 2 & 1 & 1.63 & 0.12 & 0.35 & & &
\end{tabular}

Table 2 - Parameter Values - Europe and Central Asia

\begin{tabular}{llllllll}
\hline \multicolumn{7}{c}{ Production and Utility } \\
\hline$g_{Y}$ & $\beta$ & $\delta_{P}$ & $\tau$ & $\rho$ & $C / Y^{D E}$ \\
\hline 0.128 & 0.31 & 0.01 & 0.8 & 0.01 & 0.81 \\
\hline \multicolumn{7}{c}{ Social and Human Capital } \\
\hline$\xi$ & $\delta_{H}$ & $\alpha$ & $\omega$ & $\Omega$ & $\psi$ & $\sigma$ & $\eta$ \\
\hline 0.048 & 0 & 0.01 & 0.01 & 0.01 & 0.2 & 0.08 & 0.34 \\
\hline \multicolumn{7}{c}{ Natural Capital } \\
\hline$\varphi$ & $\epsilon$ & $\kappa$ & $\nu$ & $\phi$ & & \\
\hline 1.20 & 1 & 0.88 & 0.35 & 0.35
\end{tabular}


Table 3 - Parameter Values - Low Income Countries

\begin{tabular}{cccccccc}
\hline \multicolumn{8}{c}{ Production and Utility } \\
\hline$g_{Y}$ & $\beta$ & $\delta_{P}$ & $\tau$ & $\rho$ & $C / Y^{D E}$ & & \\
\hline 0.0055 & 0.16 & 0.01 & 0.8 & 0.01 & 0.90 \\
\hline \multicolumn{8}{c}{ Social and Human Capital } \\
\hline$\xi$ & $\delta_{H}$ & $\alpha$ & $\omega$ & $\Omega$ & $\psi$ & $\sigma$ & $\eta$ \\
\hline 0.0255 & 0 & 0.01 & 0.01 & 0.0055 & 0.2 & 0.08 & 0.47 \\
\hline \multicolumn{7}{c}{ Natural Capital } \\
\hline$\varphi$ & $\epsilon$ & $\kappa$ & $\nu$ & $\phi$ & & \\
\hline 3 & 1 & 2.86 & 0.37 & 0.35 & & & \\
\hline
\end{tabular}


Table 4 - Results on Distortions

\begin{tabular}{|c|c|c|c|c|c|c|}
\hline & $K_{S} / K_{H}$ & $C / Y$ & $u_{Y}$ & $u_{H}$ & $u_{S}$ & $u_{N}$ \\
\hline & \multicolumn{6}{|c|}{ World } \\
\hline Social Planner & 0.08 & 0.888 & $62.6 \%$ & $33.5 \%$ & $3.8 \%$ & $0.1 \%$ \\
\hline \multirow[t]{2}{*}{ Decentralized Equilibrium } & 0.05 & 0.89 & $63.3 \%$ & $34.1 \%$ & $2.6 \%$ & $0 \%$ \\
\hline & \multicolumn{6}{|c|}{ Europe and Central Asia } \\
\hline Social Planner & 0.095 & 0.809 & $47.7 \%$ & $41.8 \%$ & $10.4 \%$ & $0.04 \%$ \\
\hline \multirow[t]{2}{*}{ Decentralized Equilibrium } & 0.067 & 0.810 & $50.3 \%$ & $42.4 \%$ & $7.3 \%$ & $0 \%$ \\
\hline & \multicolumn{6}{|c|}{ Low Income Countries } \\
\hline Social Planner & 0.228 & 0.893 & $68.1 \%$ & $23.9 \%$ & $7.8 \%$ & $0.2 \%$ \\
\hline Decentralized Equilibrium & 0.156 & 0.9 & $68 \%$ & $26.7 \%$ & $5.3 \%$ & $0 \%$ \\
\hline
\end{tabular}


Table 5 - Results on Distortions - Low Income Countries $(\sigma=\kappa=0)$

\begin{tabular}{lllllll}
\hline & $K_{S} / K_{H}$ & $C / Y$ & $u_{Y}$ & $u_{H}$ & $u_{S}$ & $u_{N}$ \\
Social Planner & 0.131 & 0.893 & $67.3 \%$ & $27.71 \%$ & $4.46 \%$ & $0.5 \%$ \\
\hline Decentralized Equilibrium & 0.132 & 0.9 & $67.8 \%$ & $27.67 \%$ & $4.49 \%$ & $0 \%$ \\
\hline
\end{tabular}

